Bailey, DeeVon, Eluned Jones, and David L. Dickinson (2002), Knowledge Management and Comparative International Strategies on Vertical Information Flow in the Global Food System. American Journal of Agricultural Economics, 84(5): pp. 1337- 44. (Dec 2002) Published by Wiley-Blackwell. (ISSN: 1467-8276) The definitive version is available at

Knowledge Management and Comparative International Strategies on Vertical Information Flow in the Global Food System

By

DeeVon Bailey, Eluned Jones, and David L. Dickinson

AMERICAN JOURNAL OF AGRICULTURAL ECONOMICS 


\section{Knowledge Management and Comparative International Strategies On Vertical Information Flow in the Global Food System}

The appearance of "mad-cow" disease (Bovine Spongiform Encephalopathy, or BSE) in Europe and Japan, widely publicized outbreaks of E. coli O157:H7 contamination of ground beef products and other microbiological contamination scares in the food industry, and the recent StarLink crisis have led to rising public concern worldwide for food safety. The events on September 11, 2001 added a dimension of bio-security, or intentional contamination in comparison with 'accidental' contamination (Jones (2002b)). The impact of these scares on consumers, and the reaction of government and private industry to these crises, have significant implication for how food ingredients are assembled, produced, distributed, and marketed domestically and worldwide.

The governance institutions for agri-food markets in western, democratic economies have evolved over the past hundred years to take into consideration aspects of geographic space, time relating to production cycles, storability and 'windows' of market opportunity, and inspection of the product according to physical characteristics that will ensure that the product delivered meets minimum standards of identification and functionality. While much of the World's population is primarily concerned with ingesting sufficient calories for survival, the western democracies and emerging market economies have experienced two decades of increasing disposable income paralleled with advances in health and medical science. The result is a significant market population that is focused on food as a source of nutrition, health and lifestyle. However, there is a continued expectation that the food they consume is safe.

In Schlosser's Fast Food Nation the lack of transparency in the food system was brought to the attention of the consumer in a dramatic and sensational (non-fiction) 
exposé. In a fictional setting Cook elaborated on the sensational potential of resistant $E$. coli $\mathrm{O} 157: \mathrm{H} 7$ contamination of the ubiquitous fast food hamburger by using this as the focus of his mystery, Toxin. Further, by adding a list of references for 'real' events as an appendix to a fiction novel Cook creates credibility with the reader, that this could really happen, where fantasy fiction may have none.

The first significant challenge to the ability of the food system to meet industry and consumer demands evolved from the cross-over from animal to humans of BSE resulting in the variant form of Creutzfeld Jacob Disease (vCJD). The impact of this devasting disease on the human physiology was not immediately apparent, and the latent expression of the disease caused delay in the scientific community's ability to respond to this phenomenon. Subsequently, the 'passport" ${ }^{1}$ system, incorporating the concepts of traceability, transparency, and assurances (TTA) into the red-meat system, was introduced to meet the new demands for accountability and responsiveness (recall) (Baines and Davies (1998)).

Early versions of TTA protocols were initiated in separate geographic regions of the UK and the European Union (EU), including the Scottish Quality Beef and Lamb Assurance (SQBLA) and the Farm Assured Welsh Lamb (FAWL) protocols. Multiple acronyms representing supposedly the same assurance was confusing for the consumer, resulting in the National Farmers Union (NFU) creating the 'little red tractor' label. This label was first introduced at the retail level in 2000 and had gained recognition by $60 \%$ of consumers surveyed in a 2001 survey. This umbrellas program approach is also being adopted by the EU in their EUREP or EUREPGAP approach to developing an umbrella for EU TTA protocols (Jones (2002a)). 
Other countries including Canada, Australia, New Zealand, and Uruguay are following the lead of the EU in incorporating TTA into their own red-meat systems. However, the United States (US) has not generally been incorporating TTA into its redmeat marketing system. The result is a contrast between the US red-meat system and its trading partners and competitors in terms of TTA (Liddell and Bailey; Bailey and Hayes; Lewis).

The StarLink crisis is another example of the havoc that can be caused when food inputs and products are co-mingled without regard for their origin. ${ }^{2}$ StarLink gave a "wake-up" call about how difficult it would be to track and extract contaminated grain from the US supply chain (Jones (2002a)). Strong economic incentives have existed for sometime in Europe for agricultural producers to implement quality assurance protocols. However, even in the United States some private supply chains are moving toward similar systems. For example, General Foods claims that by 2005 all of their food ingredients will be sourced via supply chain alliances and partnerships in order to control their risk exposure and to realize the profit opportunities from value enhanced products (Jones (2002a)).

Recent research suggests the US food system is lagging other countries in the development of TTA in terms of providing traceability, transparency, and extrinsic quality assurances (Liddell and Bailey; and Jones (2002a)). The fact that food systems in different parts of the world are incorporating TTA at varying rates and for different purposes results in different protocols, and complicates communication and informational flows among the different systems. This type of disharmony causes difficulties in trade and also increases confusion among consumers and others along the marketing chain. In 
fact, among policy-makers, the requirement by UK flour millers that all wheat ingredient supplies must originate from sources certified by the Assured Combinable Crops program, or an equivalent, is viewed as a non-tariff barrier to trade. However, blending imports not sourced from a TTA certified entity with domestic supplies would negate the ability to source verify, and discriminate against domestic (UK) wheat producers. ${ }^{3}$

\section{Definitions}

Traceability is defined as the ability to track the inputs used to make food products upstream to their source at different levels of the marketing chain. Liddell and Bailey go further to say that "complete" traceability would require not only being able to trace back the principal inputs in food products to their source at different levels of the marketing chain, but also the secondary inputs such as feed stuffs and genetic lines in the case of red meat.

Transparency refers to the public disclosure of information on all of the rules, procedures, and practices used to produce a food product at each level of the marketing chain (Baines and Davies (1998); Early). Transparency provides consumers with detailed information about the processes used to produce a food product. This eliminates the "black box" of production practices and informs consumers about how the product was produced and even elicits input from consumers about the procedures they would like used to produce the product.

Quality assurance has three key elements including 1) managing hygiene to ensure food safety, 2) ensuring quality through grading and other measurements, and 3) providing mechanisms for product recalls (Early; Baines (2001)). The processes for ensuring hygiene in the EU for red meat have focused on Hazard Analysis Critical 
Control Point (HACCP) protocols at each point in the pork value chain. ISO-9000 and other ISO protocols are also being used for a wide range of food products not only to certify hygiene but to also certify social and environmental responsibility (e.g., ISO14000).

Ensuring quality includes measurements of the intrinsic quality of a commodity or food product (taste, grading, etc.). Intrinsic quality measurements of physical traits are common to most government grading systems including the United States, its trading partners, and competitors. However, measurement of biochemical and bioengineered traits that have either positive (health, processing efficiency) or negative (possibly genetically engineered in some markets) credence value in the supply chain is limited by the technological ability to measure the traits and/, or the economics of measuring a representative sample of the population.

In response to consumer demand, the EU system also provides measures of the extrinsic qualities of food products, especially red meat. Extrinsic qualities do not affect either food safety or the intrinsic qualities of the food product but may still affect the value of the product. Extrinsic qualities could include assurances about animal welfare, environmental preservation, social responsibility, or assurances about the absence of inputs used to produce the food product such as the absence of genetically modified organisms (GMOs) (Liddell and Bailey; and Baines (2001)). Extrinsic quality assurances have the potential, along with traceability, transparency, and other certification and labeling standards (e.g., ISO) to provide a basis for differentiating food products both in international trade and domestic markets (Baines and Davies (2000)). For example, in 
the UK customers are willing to pay approximately $\$ 0.15$ per $1 / 2$ dozen eggs more for "free range" eggs than for fresh barn eggs.

\section{Potential Impact on the US Food Chain}

There are at least four reasons why the US food industry should be concerned that it is lagging its competitors in terms of TTA. First, consumers are becoming more concerned about the inputs used to produce food. In the past, consumers viewed their primary food safety risk as being food-borne pathogen contamination at the processing and preparation levels. As a result, current US food inspection, food safety laws, and enforcement are aimed principally at food processors and food preparers. Food-borne pathogens remain an important concern but emerging consumer interest centers on the inputs used to produce food such as concerns about genetically modified organisms (GMOs), the effect of consumption on environmental degradation, and animal welfare issues. The current US inspection system was not designed to track farm-level inputs in food production and significant changes, and associated costs, would be required to modify the US system to do so.

Second, competitors may be able to successfully differentiate their food products based on TTA (Baines and Davies (2000)). This could conceivably relegate US food products to second-class status in the eyes of some consumers resulting in a loss of market share in international trade. The reverse example might be where market share was gained by some suppliers being able to source-verify corn during the StarLink crisis and provide documentation that the grain was not contaminated with StarLink corn (e.g., Consolidated Grain and Barge who are implementing ISO protocols across their country elevators). 
Third, domestic and foreign consumers may be willing to pay for TTA and a potential market opportunity may be lost if the US food industry fails to develop credible TTA systems. Fourth, the security of the food system may require a method for tracking food and food inputs rapidly to their source. A major US food processor has suggested a target of ten minutes for tracing the point of contamination and issuing recall information. The current system co-mingles products from many producers in many locations making them almost impossible to track. The intentional contamination of food ingredient supply chains is an issue of greatest concern to US processors and manufacturers. Implementing TTA protocols can highlight the critical points for controlling assurance and traceability, and can provide the framework for documentation. Further efforts would be required to protect the supply chains against efforts intentional contamination. However, without the TTA framework the ability to recall contaminated food ingredients upstream from the processor is minimal regardless of the timeframe.

\section{Sources of Friction between Food Systems}

\section{Food Policy Relating to Risk Assessment and Risk Analysis}

The development of TTA systems and the rise of the "precautionary principle" (PP) in public food policy in the EU signals a system experiencing a severe breakdown in communication along the marketing chain. The PP has long been associated with environmental protection policy and was instituted to sanction remediation action where lack of full scientific certainty of the outcome existed, e.g. the impact of an oil spill on wildlife and the environment. In response to tightening product liability and due diligence legislation in the early 1990's in the UK and the emerging BSE crisis, the PP began to be applied to address food policy concerns in the EU (Davies). The PP applied 
to food policy basically states that short-term food policy decisions may have long-run consequences but are often made without conclusive scientific evidence of the absence of any long-run harm. Consequently, precaution should be exercised in developing policy without conclusive scientific evidence (Davies). Thus, in the trade policy debate the PP has been used to paralyze action where non-zero risk is present, such as in the introduction of genetically modified corn and soybeans that have been altered to resist specific herbicides. While this does not necessarily mean that a food product must be proven to have no significant risk to human health, it may mean that significant restrictions on the sale of the product or strict labeling may be required (Davies).

The US food industry has usually resisted these types of restrictions by the EU on the grounds that 1) the restrictions can be applied even in the absence of scientific evidence of potential harm and 2) the restrictions principally affect products imported into the EU and are in fact trade barriers. The most notable conflicts that have arisen as a result of these differences are the EU ban on US beef because of added growth hormones and the more recent controversy about genetically modified (GM) foods and food ingredients.

\section{Role of Public and Private Sectors in TTA}

Current TTA systems in the EU developed as partnerships between the public and private sectors designed to restore consumer confidence in the safety of EU food systems following the BSE crisis. Public assurances by European governments that there was no evidence that BSE was transmissible to human, together with the perception that government undertook inadequate measures to protect the public once a danger to consumers was acknowledged, left European consumer confidence in their government's 
ability to assure the EU food supply badly shaken (Baines and Davies (1998)). Private companies and producer associations in some EU countries attempted to bolster diminished consumer confidence by developing brand names that gave private certifications regarding food safety and quality assurance including TTA (e.g., Assured British Meat (ABM) and Swedish Farm-Assured).

Baines and Davies (1997 and 2000) have argued that both public and private sector involvement are necessary for effective TTA programs. They cite the initial efforts in the UK to provide private assurances, especially about enhanced food safety, which resulted in confusion at all levels of the marketing chain about what was being assured, and by whom. To counter this confusion, ABM was developed as a method to consolidate programs and to develop minimum standards for food safety, environmental preservation, animal welfare, and traceability (Fearne; Baines and Davies (2000); Early). $\mathrm{ABM}$ requires that a product have TTA in order to be marketed under the $\mathrm{ABM}$ brand name. Other countries, such as Canada, Australia, New Zealand, and Uruguay, have or are attempting to harmonize their systems with that of the EU and have adopted the private/public partnership model (Liddell and Bailey; Lewis). After recent confirmed cases of BSE in Japan, the Japanese government has also indicated they plan to move toward an EU-style animal identification and tracking system for red meat (Dawson).

In the past in the US, issues relating to TTA have been driven principally by concerns about the costs and benefits of implementing such systems. This is in contrast to the EU where consumers have demanded that agribusiness firms initiate TTA systems as a prerequisite to selling food products. For example, Wiemers once stated that traceability systems for red meat would not be employed in the United States unless 
consumers were willing to pay more for products with TTA characteristics. Many US agricultural producers have resisted the notion of implementing TTA in the United States for one or more of the following reasons: 1) They believe TTA is being forced on the US food system as a result of problems in the EU that do not exist here, 2) they believe that implementing such systems unnecessarily raises consumer concerns about food safety, or 3) they believe that imposing traceability on the US system exposes producers to potential liability beyond what they typically have faced in the past (Todd). These concerns have resulted in the US food system being slower to react to these developments than some of our major trading partners and competitors.

\section{Industry 'Captains' in the Food System}

A key difference in the rate of adoption of TTA protocols lies not only in the lack of a life threatening crisis relating to the US food system, but in who drives the food system. In western Europe, the food retail companies, who evolved as the industry captains with integration back into the food manufacturing and processing level of the supply chain, have embraced TTA (e.g., Carrefour, Ahold, and Tesco). Seven of the top ten global supermarket companies, by sales revenue, are western European, while the first, third and sixth are US companies. Only WalMart, the number one global retailer, has an international presence in the food retail market. Conversely, in the United States the processors and manufacturers have historically maintained control over the food supply chain (e.g., ConAgra and Kraft/Philip Morris). However, the European retail model has entered the US food system through Ahold (Giant Supermarkets) at the retail level and Nestle and Unilever in the processing and manufacturing levels (Jones, 2002b). 
Carrefour, a French company, is a global leader with presence in central and south America, Asia as well as across western and eastern Europe.

With the processor and manufacturer as the industry captains of the US food system, ensuring traceability requires building relationships in both directions along the supply chain--forward to retail and backwards to the farm level. Given current technology in bar-coding and the use of information technology to provide efficient customer response and reduce inventory holdings, the ability to trace forward is of less concern to processors than their ability, or lack thereof, to trace ingredients to the farm. Figure 1 illustrates the typical points of transfer of ownership upstream from the processor. By incorporating deliberate 'breaks' in non-food ingredient lots, and their associated bar-code or tracking system, used in assembly the ability to ensure recall can be incorporated. Similarly, manufactured ingredients such as flavorings and preservatives can be handled in bulk lots that are coded and used in volumes that enable efficient and economic recall. Packaging materials and manufactured ingredients pose less of a threat from unintentional contamination, but are still at risk for bio-security concerns.

The weakest link in the food supply chains occurs where the ingredients are blended, fungible commodities. Animals are individual and separable entities until the carcass is broken up at the slaughter house. At this point, the opportunities for traceback are limited by the amount of information that is included with the partial carcasses and eventual cuts of meat. Of greatest concern is the ground beef that is formed from numerous sources of 'renderings'. In the grains and oilseed industry, the integrity of the origin is lost when the grain is blended with other sources of grain at the country elevator. 
Information on the individual farm businesses from which the grain originated is rarely associated with the elevator bin contents, and is consequently not passed downstream to the commercial elevator or to the food or feed processor. Attempts to retain credence traits through the elevator system have been successful in the High Oil Corn supply chain through a series of contracts with the country elevators, and subsequently to the

producers. Similarly, there are locations where higher protein wheat has been segregated to maintain value in the supply chain. However, while the traits have been retained, the information on management practices at each stage in the supply chain, and the identity of all producers and handlers associated with any 'lot' of grain by the time it reaches the mill has been lost. It is this information that is essential to TTA protocols, and the ability to recall and pinpoint with any degree of accuracy the point of unintentional or intentional contamination (Jones, 2002b).

\section{Potential Costs and Benefits of Implementing TTA}

While the EU has focused on implementing TTA as a foundation of its food marketing system, initial efforts in the US food system have focused on exploiting niche markets opportunities for TTA products. These efforts suggest that a significant number of US consumers are willing to pay for TTA products although little, publicly-available, economic research has been completed concerning willingness to pay for such products. For example, Farmland Foods and Premium Standard Farms market pork products with TTA characteristics.

To our knowledge, the only publicly-available study completed in the United States directly examining consumer WTP for TTA was conducted by Dickinson and Bailey, although other studies have examined WTP for characteristics that could be 
verified using traceability (e.g., Lusk and Fox; Lusk, Roosen, and Fox; Grannis, Hooker, and Thilmany). Dickinson and Bailey suggest that the potential market for TTA red-meat products appears to be large. Their study uses economic experiments to determine WTP and indicates that US consumers will pay a significant, non-negative amount for traceability in both beef ( $8 \%$ above base) and pork ( $22 \%$ above base). ${ }^{4}$ However, US consumers were willing to pay even more for roast beef having animal welfare and food safety ${ }^{5}$ characteristics than they are for traceability alone. This suggests that traceability is best "bundled" with other types of characteristics. Bailey and Dickinson also report that a general market may exist for TTA characteristics for beef in the US while pork appears to be a niche-oriented market.

There is a significant cost associated with implementing TTA systems. Buhr reports that one company in the EU has invested approximately \$14 million in its program. Coe reports an investment by Global Animal Management of approximately $\$ 10$ million to develop a computer-based animal, tracking database system. Coe also estimates a cost to participants along the marketing chain ${ }^{6}$ of between $\$ 10$ and $\$ 15$ to track and store data from birth to retail for each head of beef. This cost reflects only the costs of buying ear tags and the tracking service and does not reflect labor costs and other investments at each level of the marketing chain.

TTA systems will require significant changes in record keeping systems and may also require changes in how animals are handled and housed. Additional research needs to be completed to make accurate estimates of these costs. At least some of the return on the investment will be realized through increased management efficiencies resulting from information flows up and down the channel. Nothing is known about the demand 
elasticity for TTA in the US, but these figures suggest that at least some marketing chains can market TTA products profitably.

Determining the cost of compliance with TTA protocol requirements depends on the current level of record keeping at the farm-to-first handler level of the supply chain, which is the weakest link in the food ingredient supply system. If computerized records of the activities such as variety, pesticide use, fertilization, machinery/equipment used/ management practices, scouting activities (disease/insect/crop condition), harvest, and handling (binning and movement to commercial elevator) are already kept at the field level of record keeping, the added costs of implementing TTA protocols are minimal. However, if producers are not keeping computerized records at the crop or farm level, the added costs of implementing TTA protocols will appear onerous.

The relationship of costs versus benefits can change dramatically if the risk associated with life threatening contamination is considered. To the downstream food industry the cost of a product-related death will outweigh the costs of implementing TTA to many in senior management. The impact is a death knell to a brand, domestic and global market positioning and share, and possibly to the company (e.g., Hudson Foods). Thus, the implementation of TTA may be viewed as a long run investment. At the farm level the commodity producer is several steps removed from the perspective of their output as "food" and rarely carries product liability insurance. Unless held accountable for contamination in any form the producer is unlikely to consider the costs as a necessary part of doing business. 


\section{Conclusions}

Food markets in developed and emerging economies are evolving toward systems requiring accountability at each stage of production. This accountability is being ensured by protocols that require a new level of knowledge management that focuses on the processes that produce products rather than simple inspection of the products themselves. Process control is enabled by information technology and can create value if the information is used to provide assurances to consumers for which they are willing to pay. This information also can be extended to create knowledge in the food system that would enable rapid trace back in times of crisis (recall or intentional contamination).

While TTA has become a more general requirement in some markets, such as the EU, it has been primarily a niche market strategy in others, such as the United States. From the perspective of marketing, whether dichotomous food systems can continue to exist or not depends principally on the ability of the different systems to trade in different markets. There is significant evidence to suggest that pressure will continue to exist to provide more information on input sources and the processes used to produce food products. Designing systems that effectively gather and communicate information along the marketing chain about production processes and inputs will demand the attention of agri-business firms. Economic research dealing with the costs and benefits of such systems and protocols is also needed. 


\section{References}

About.Com: Website available at http://retailindustry.about.com/library/bl/q3/bl_pwc top100.htm, May 14, 2002.

Allied Mills and Rank Hovis McDougall. Personal communication, June 2001.

Bailey, D., and D. Hayes. "The Evolution of Identity Preservation in Red Meats." Managing for Today's Cattle Market and Beyond. Website available at http://ag.arizona.edu/arec/wemc/cattlemarket/Evolution_of_Identity_Preservat. May 14, 2002.

Baines, R. N. Personal communication, September 2001.

Baines, R.N., and W. P. Davies. "Food Quality Assurance: Public Perceptions and International Benchmarks." Globalization and the Food Industry: Policy Implications. R. J. Loader, S. J. Henson, and W. B. Trail eds., pp. 109-124. University of Reading, England, 1997.

Baines, R. N., and W. P. Davies. "Meeting Environmental and Animal Welfare Requirements Through On-Farm Food Safety Assurance and the Implications for International Trade.” Paper present at the 2000 Agribusiness Forum of the 2000 World Food and Agribusiness Congress, Chicago, IL, June 2000.

Buhr, B. "Electronic Traceability in European and US Meat Supply Chains." Paper presented at National Pork Industry Forum, Denver, CO, February 28, 2002.

Coe, M. Global Animal Management. Personal communication, April 2002.

Cook, R. Toxin. New York: MacMillan, 1998. 
Davies, S. "The Precautionary Principle and Food Policy." Consumer Policy Rev., 12(Mar/Apr 2002):65-72.

Dawson, C. "Call it Cattle-Logging." Business Week, December 3, 2001, p. 16.

Dickinson, D. L. and D. Bailey. "Meat Traceability: Are US Consumers Willing to Pay for It?" J. Agr. and Resour. Econ., in press.

Early, R. "Farm Assurance—Benefit or Burden?" J. Royal Agr. Soc., 159(1998):32-43.

Farmland Foods. Website available at www.farmlandfood.com, April 22, 2002.

Grannis, J., N.H. Hooker, and D. Thilmany. "Consumer Preference for Specific Attributes in Natural Beef Products." Paper presented at WAEA annual meetings, Vancouver, British Columbia, June 29-July 1, 2000.

Jones, E. "Entity Preservation and Passport Agriculture: EU vs. USA.” Drake J. of Agr. Law, in press, 2002a. Also paper presented at the American Agricultural Law Association Annual Meetings in Colorado Springs, CO, October 13, 2001. . "The Economics of Assurance and Traceability - Is This the Same as Identity Preserved?" Paper presented at Milling and Baking Technical Meetings, American Association of Cereal Chemists, Omaha, NE, May 2002b.

Lewis, S. "Uruguay Establishes Livestock Traceability Commission.” Food Traceability Report, 1(November 2001):10.

Lusk, J. L., and J. A. Fox. "Consumer Demand for Mandatory Labeling of Beef from Cattle Administered Growth Hormones or Fed Genetically Modified Corn." J. Agr. and Appl. Econ., 34(April 2002):27-38. 
Lusk, J. L., J. Roosen, and J. A. Fox. "Demand for Beef from Cattle Administered Growth Hormones or Fed Genetically Modified Corn: A Comparison of Consumers in France, Germany, the United Kingdom, and the United States.” Amer. J. Agr. Econ., in press.

National Farmers Union Websites available at http://www.nfu.org.uk and http://www.littleredtractor.org.uk, April 22, 2002.

Premium Standard Farms. Website available at www.psfarms.com, April 22, 2002.

Roosen, J., J. L. Lusk, and J. A. Fox. "Consumer Demand for and Attitudes Toward Alternative Beef Labeling Strategies in France, Germany, and the UK." Paper presented at AAEA annual meetings, Chicago, IL, August 5-8, 2001.

Schlosser, E. Fast Food Nation. New York, NY: Houghton Mifflin Company, 2001.

Swedish Farm Assured. Website available at http://www.healthytasty.com/Trace/index.htm, April 19, 2002

Todd, T. "The Era of Traceability is Coming." Western Livestock Journal, February $26,2001$.

Wiemers, J. F. Chairman of USDA, FSIS Interagency Commi8ttee on Animal Identification. Paper presented at Attacking Global Food and Agribusiness Barriers Conference, George Mason University, Fairfax, VA, March 13, 2001. 
Figure 1. Ingredient Supply Flow in Domestic Food Processor/Manufacturing.

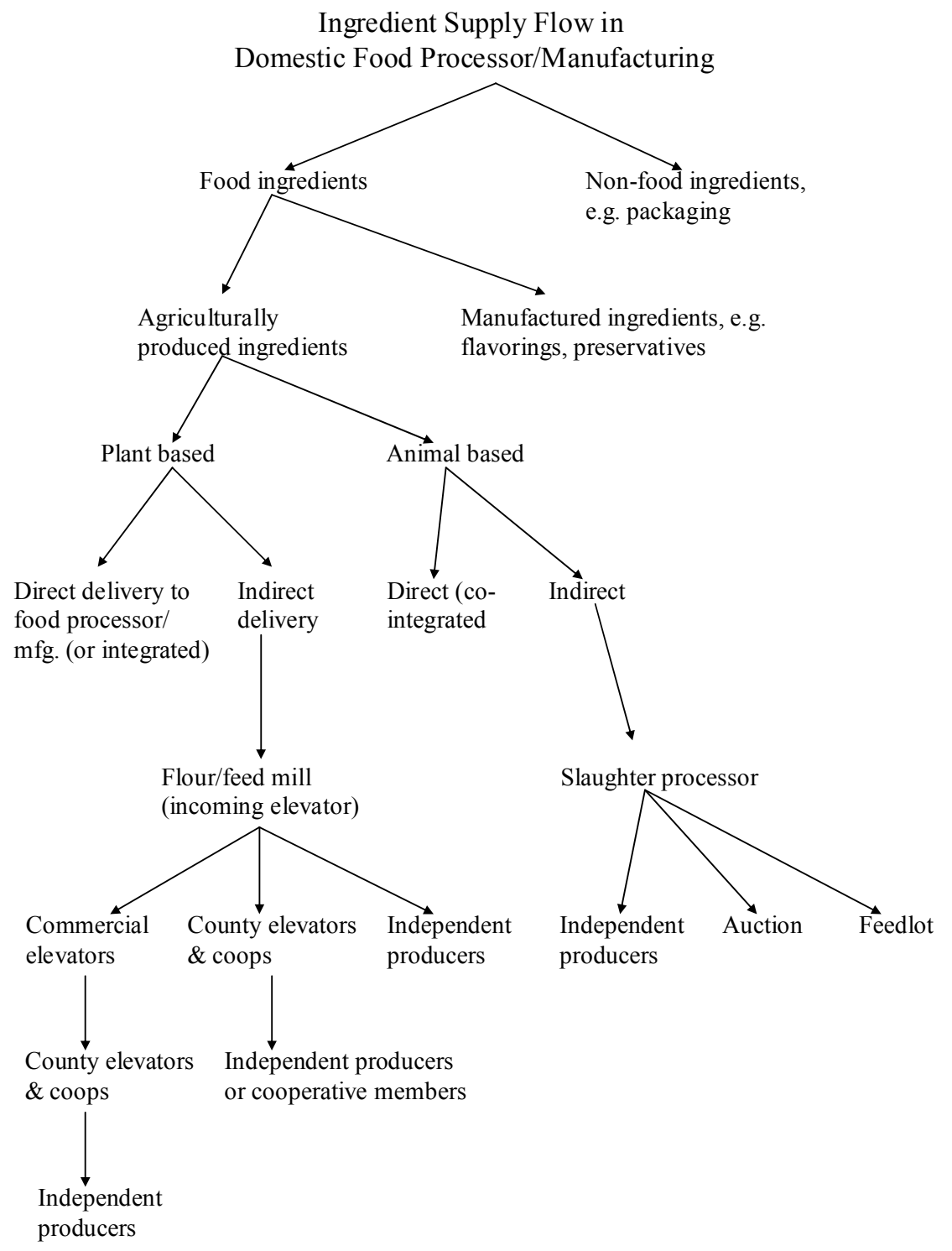


1 'Passport' indicates that all movements from birth to table of the animal, and parts thereof, are documented to enable rapid traceback of meat from retail to the farm. This system, first employed for beef as a paper trail in the UK, is now a computerized system to enable transfer of data and information electronically.

${ }^{2}$ It's estimated that it cost Aventis, the company that developed StarLink, was as much as $\$ 500$ million to track and extract it from the human food system once it had entered that system (Food Traceability Report).

${ }^{3}$ Allied Mills and Rank Hovis McDougall.

${ }^{4}$ Since these data are generated under experimental conditions, they should be considered as upper bounds on WTP.

${ }^{5}$ Animal welfare is a process certification (transparency) while food safety is an enhanced assurance.

${ }^{6}$ Investments are made by each level of the marketing chain but total somewhere in the $\$ 10-\$ 15$ range. 